\title{
Image of the Month
}

\section{EEG in lissencephaly}

\section{Suvasini Sharma*, Puneet Jain, Satinder Aneja}

Department of Pediatrics, Lady Hardinge Medical College and Associated Kalawati Saran Children's Hospital, New Delhi 110001, India

\section{A R T I C L E I N F O}

Article history:

Received 10 September 2013

Accepted 11 December 2013

\section{A B S T R A C T}

We report the characteristic EEG findings of an infant with lissencephaly who presented with infantile spasms.

Copyright @ 2014, Indian Epilepsy Society. Published by Reed Elsevier India Pvt. Ltd. All rights reserved.

Keywords

Migration disorders

Epilepsy

Diffuse theta

An eight-month-old male presented with developmental delay and flexor spasms for the last 2 months. He was the first child of non-consanguineous marriage. The antenatal and perinatal periods were uneventful. He achieved social smile at 5 months, partial neck holding at 6 months and was recognizing his mother and cooing at the time of presentation. There was no grasp. There was no regression of attained milestones. He had started having flexor spasms since the last 2 months. The spasms occurred in clusters mainly on waking up from sleep. He also had stiffness in the lower limbs which had been noticed for the last 2 months. This was non-progressive. Vision and hearing were normal. The family history was uneventful.

On examination, the child had normal facies and no neurocutaneous markers. The weight and length were age appropriate. He had microcephaly (OFC $39.5 \mathrm{~cm}$ ). The cranial nerve examination was normal. The tone was increased in all 4 limbs with brisk deep tendon reflexes and extensor plantar responses. Systemic examination was unremarkable. The MRI of the brain showed lissencephaly with no gradient (Fig. 1). The EEG showed diffuse high voltage theta activity (Fig. 2).

* Corresponding author. Department of Pediatrics, Lady Hardinge Medical College and Associated Kalawati Saran Children's Hospital, New Delhi 110001, India.

E-mail address: sharma.suvasini@gmail.com (S. Sharma). 2213-6320/\$ - see front matter Copyright @ 2014, Indian Epilepsy Society. Published by Reed Elsevier India Pvt. Ltd. All rights reserved. http://dx.doi.org/10.1016/j.ijep.2013.12.001

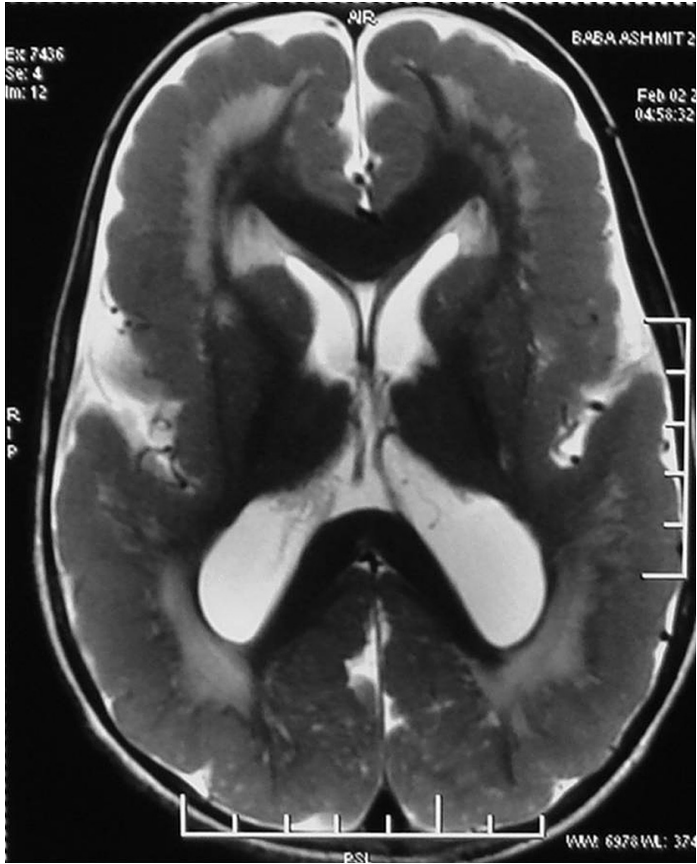

Fig. 1 - T2 axial MRI image of the brain at the level of the basal ganglia showing thickened cortex with no gradient, suggestive of lissencephaly. 


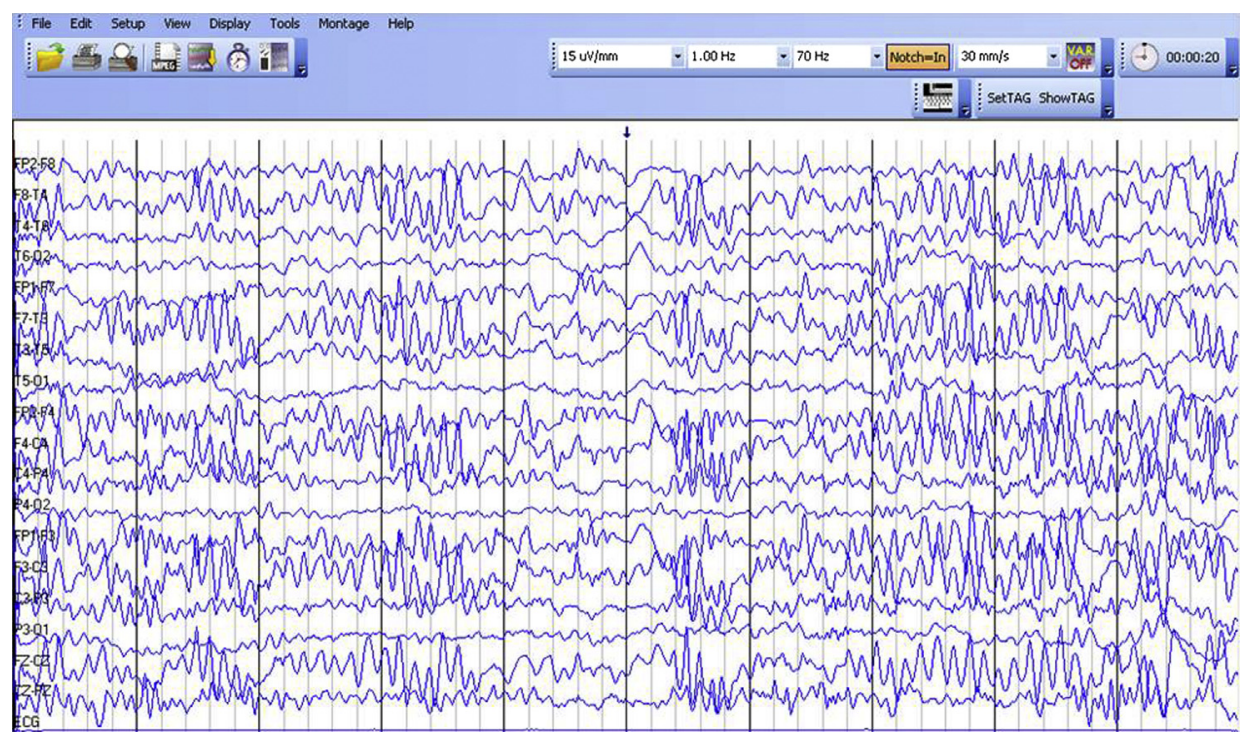

Fig. 2 - EEG showing diffuse high voltage bisynchronous theta activity with amplitude fluctuations of cortical activity attenuation lasting 2-3 s (sensitivity $15 \mu \mathrm{V} / \mathrm{mm}$ ).

Lissencephaly is a disorder of neuronal migration characterized by absent or abnormally wide gyri and abnormally thick cortex. Epilepsy is a major presentation of lissencephaly syndromes and is usually drug-refractory. ${ }^{1}$ Three EEG patterns have been classically described in patients with lissencephaly. ${ }^{2}$ EEG pattern type I consists of diffuse high amplitude, greater than $100 \mathrm{mV}$, alpha and beta activity in all cortical regions. EEG pattern II shows alternating high amplitude, up to $300 \mathrm{mV}$, bursts of sharp and slow waves, followed by short duration periods of attenuation of cortical activity that last up to $3 \mathrm{~s}$. EEG pattern III is characterized by high amplitude spike waves or sharp wave activity, without alpha or beta frequencies, or attenuations of the cortical activity. $^{3}$ The current case showed EEG pattern II. The characteristic EEG patterns along with the clinical findings may help neurologists to consider the diagnosis of lissencephaly.

\section{Conflicts of interest}

All authors have none to declare.

\section{REFERENCES}

1. Guerrini R. Genetic malformations of the cerebral cortex and epilepsy. Epilepsia. 2005;46(suppl 1):32-37.

2. Hakamada S, Watanabe K, Hara K, Miyazaki S. The evolution of electroencephalographic features in lissencephaly syndrome. Brain Dev. 1979;1:277-283.

3. Menascu S, Weinstock A, Faroog O, Hoffman H, Cortez MA. EEG and neuroimaging correlations in children with lissencephaly. Seizure. 2013;22:189-193. 